\title{
Development of Forms of Interaction Between the Authorities and Business in the Field of Physical Education and Sports in Russia
}

\author{
Yana V. Savchenko \\ Ural State University of Economics \\ USUE \\ Yekaterinburg, Russia \\ 75karpenko@mail.ru
}

\author{
Lyudmila A. Ramenskaya \\ Ural State University of Economics \\ USUE \\ Yekaterinburg, Russia \\ ramen_lu@mail.ru
}

\begin{abstract}
The paper investigates the dynamics of the development of modern forms of interaction between the authorities and business in the field of physical education and sports in the Russian Federation, which is caused by the need on the part of the State to reduce funding for this sphere and, accordingly, increase the share of private investment in the implementation of infrastructure social projects. The methodological basis of the study was the theory of public administration, the theory of public-private partnership, project management. The study identifies the main areas within which the interaction between the authorities and business in the field of physical education and sports is implemented. Periodization of the development of forms of interaction between business and the authorities in the field of physical education and sports in Russia has been carried out. A quantitative and in-depth substantive analysis of the projects of interaction between the State and business in the field of physical culture and sports has been carried out. The problems that hinder the increase in the efficiency of interaction between the State and business, in particular in the framework of public-private partnership, have been identified. The analysis of common forms and models of interaction between the public side and private investors in the field of physical culture and sports made it possible to justify the need for further dissemination of various forms of interaction between the State and business, as well as the formation of a single information field that allows public and private partners to use the experience gained in this field.
\end{abstract}

Keywords-business; authorities; interaction; public-private partnership; physical education; sports.

\section{INTRODUCTION}

One of the serious problems in the development of the social sphere in Russia is the ongoing process of reducing the possibilities of its financing from the State. World practice has allowed adopting the experience of attracting private investors for the implementation of significant social infrastructure projects. This practice is implemented in various forms of interaction between the authorities and business, one of the main forms of which is public-private partnership, although it is not the only possible and sufficient one. The limited financial and managerial capacity of the State to develop the social sphere in Russia, with the right approach, can be significantly expanded due to the investment and personnel potential of private business.

\section{LITERATURE SURVEY}

The use of public-private partnership to solve the problems of financing infrastructure projects in the sports industry dates back to the $1990 \mathrm{~s}$. For the first time, this mechanism was proposed by the UK government to attract private investment in the field of sports, and, subsequently, it was widely distributed in different countries [1]. Between 2001 and 2007, more than 500 public-private partnership (PPP) contracts were launched in the UK, while in Europe during the same period 200 PPP agreements were launched [2].

The sports industry is considered to be attractive enough to use various forms of interaction between the authorities and business. Historically, a large selection of such tools and mechanisms, widespread both in Russia and abroad, has formed. A variety of forms and models of public-private partnership allows the use of mutually beneficial terms of the contract for the parties, among which the distribution of risks, financial model, the responsibility of the parties, etc. can differ significantly. The concept of "public-private partnership" (PPP), which, however, is rather vague, and, in different countries, implies different mechanisms and forms of interaction between public and private partners, has become widespread. So, in the world practice, the participation of business in the sports sector has become the most widespread in the following areas:

- holding major sporting events of international level. So, the 2012 London Olympics are recognized as one of the brightest examples of public-private partnership in sports [3]; 
- imperfection of control mechanisms, which, on the one hand, should be sufficient to detect problems in the early stages [14], and, on the other hand, not be extremely bureaucratic;

- the provision of services in the field of sports, sporting events, safety during sporting events, the management of sports facilities, etc. [1];

- training of sports specialists and professional athletes, development of national sports standards, production of goods for the sports industry [5].

Countries actively using partnerships between the State and business for the development of sports include the United Kingdom, USA, France, Spain, Italy, Greece, Germany, Portugal, India, Singapore, South Africa, and others.

The forms and mechanisms of interaction between the authorities and business are very diverse. In world practice, these include: corporatization, a joint venture, economic zones, concessions, state contracts, production sharing agreements, leases (leasing), private financial initiative, a life cycle contract, preferential taxation, an agreement on socioeconomic cooperation, etc. [2, 3, 6].

In Russia, 3 areas of relations between public and private partners in sports have spread:

1) When implementing megaprojects and major sporting events, such as the Olympic Games, World Championships, Universiades.

In large-scale sports megaprojects, the State acts as a whole complex of roles - the customer, investor, leader, as well as a representative of multiple stakeholders; this multiplicity requires a formal distribution of roles and responsibilities. Business acts mainly as an implementer of individual multi- and monoprojects.

In the terminology of project management, "megaprojects" have such characteristics as scale, duration, a large number of highly differentiated stakeholders and impact on the public, economy, and policy of the "host" country $[7,8]$.

These characteristics require the use of integrated management technologies, the use of which is complicated by the high turbulence of the external environment and, as a consequence, the exposure of such projects to various risks [9], as well as inevitable crises that can jeopardize the feasibility of the project [10].

Studies of crises that arise in megaprojects of various industries have allowed us to distinguish the following main factors of their occurrence:

- information asymmetry, which can lead to distortion of facts and corruption [11];

- conflicts related to the economic characteristics of megaprojects, which are the result of an underestimation of costs, investor opportunities [12], and the unclear distribution of roles and responsibilities between the parties [13];
- responsibility and qualifications of key stakeholders [15];

- imperfection of risk management procedures that do not take into account the mutual influence of individual projects [16].

The study of individual cases of the implementation of sports megaprojects confirms the significance of the identified problems.

Thus, a study of construction projects for the Olympic and Paralympic Games in London showed that one of the main tasks was the organization of system integration of projects, including maintaining system stability in a situation of largescale unforeseen changes [17].

Studies of the economic component of sporting events show that benefits are often overvalued and costs underestimated $[18,19]$.

2) When implementing projects in the field of physical education and sports as part of a state-private partnership.

An analysis of publications on the subject of public-private partnership has showed that the presentation of the success factors of PPP projects is very differentiated depending on the country of implementation [20, 21]. In accordance with this, the success of the project is influenced to the greatest extent by the institutional component and, to a lesser extent, by the experience of implementing foreign analogues.

In Russia, a public-private partnership is implemented in two forms: a concession agreement and an agreement on public-private partnership / municipal-private partnership (PPP/MPP). Both forms are regulated by domestic law:

a) the Federal Law dated July 21, 2005, No. 115-FZ On Concession Agreements;

b) the Federal Law dated July 13, 2015, No. 224-FZ On Public-Private Partnership, Municipal-Private Partnership in the Russian Federation and Amending Certain Legislative Acts in the Russian Federation.

The constituent entities of the Russian Federation, implementing PPP projects in the field of sports, qualify for support (subsidies) from the federal budget as a part of the Federal Target Programme Development of Physical Culture and Sports in the Russian Federation until 2016-2020.

3) When implementing projects using mechanisms not related to PPP/MPP by virtue of the Russian law.

Such forms of interaction are called "quasi-PPPs". In Russia, such forms of "quasi-PPP" are encountered as longterm investment obligations, a life cycle contract, corporate forms, leases with an investment obligation, and other forms of contractual obligations. In the field of physical education and sports, the latter has become most widespread. However, there are some cases where other forms of interaction are used. 
For example, the project "Construction of the Multifunctional Complex VTB-Arena Park - Reconstruction of the Dynamo Stadium in the Territory of Moscow" was implemented in the form of corporatization, the construction of the CSKA stadium (VEB Arena) also in Moscow - using concessional financing of VEB, and the construction of Spartak Stadium (Moscow) as a part of a sponsorship agreement on a long-term strategic partnership. All three projects have been successfully completed.

\section{RESEARCH METHODOLOGY}

The object of this study is the forms of interaction between the authorities and business in the field of physical education and sports in the Russian Federation. The information base of the study was the database of projects presented on the ROSINFRA portal "Infrastructure Project Support Platform" (http://www.pppi.ru/projects). The data have been verified through open sources of information, including the official websites of the State authorities of the constituent entities of the Russian Federation and local governments, publications in the media, normative and methodological support for PPPs and MPPs, including in the field of physical education and sports. The need to verify the official database of ROSINFRA infrastructure projects is due to the identification of discrepancies in information on the status and progress of the implementation of a significant number of projects placed in the database with the actual situation, as well as the absence of a number of PPP projects in this database.

The analysis of infrastructure projects and the normative and methodological base in the field of physical culture and sports made it possible to identify the stages of development of forms of interaction between the authorities and business in the sports industry, to determine the features and problems of these relations at the present stage.

The methods of systematization, comparison, statistical analysis, and generalization have been used.

\section{ANALYSIS OF EXPERIENCE OF PROJECT} IMPLEMENTATION WITHIN THE FRAMEWORK OF INTERACTION OF THE AUTHORITIES AND BUSINESS IN THE FIELD OF PHYSICAL CULTURE AND SPORTS

\section{A. General characteristics of the research base}

In total, the Rosinfra's infrastructure projects database currently includes 87 projects in the framework of interaction between the authorities and business in the field of physical education and sports. We added 4 more PPP projects to the sample, described in other sources of information and not in this database. To date, only 65 out of 91 have an agreement between a public and private partner. The Rosinfra website also has information on projects initiated by public partners and in search of a private investor in the initiatives section. There are 24 such projects in the Rosinfra database, excluding duplication of projects for both databases. Thus, the total number of projects at different stages of the life cycle in the field of physical education and sports is 115 . The sample does not include megaprojects for holding sporting events of an international level, based on the results of a study of which certain conclusions have been drawn.

\section{B. Analysis of the forms of interaction between business and the authorities in the framework of PPP/MPP and quasi- $P P P$}

Analysis of PPP and quasi-PPP projects in the field of physical education and sports has shown that today, 3 main forms of cooperation, provided in Table 1 , have spread.

TEBLE I. STATISTICS FOR FORMS OF IMPLEMENTATION OF PROJECTS FOR INTERACTION OF THE AUTHORITIES AND BUSINESS WITH THE FIELD OF PHYSICAL CULTURE AND SPORTS IN RUSSIA

\begin{tabular}{|l|c|c|c|}
\hline \multirow{2}{*}{$\begin{array}{c}\text { Form of interaction } \\
\text { between the authorities }\end{array}$} & \multirow{2}{*}{$\begin{array}{c}\text { The number } \\
\text { of projects, } \\
\text { and business }\end{array}$} & \multicolumn{2}{|c|}{$\begin{array}{c}\text { Level of implementation, } \\
\text { units } / \%\end{array}$} \\
\cline { 3 - 4 } & units/\% & Regional & Municipal \\
\hline concession agreement & $63 / 55$ & $29 / 25.2$ & $34 / 29.6$ \\
\hline $\begin{array}{l}\text { PPP/MPP agreement, } \\
\text { including a public }\end{array}$ & $22 / 19$ & $8 / 7$ & $14 / 12.2$ \\
partner initiative & & & $10 / 8.7$ \\
private initiative & $18 / 15.5$ & $8 / 7$ & $4 / 3.5$ \\
\hline $\begin{array}{l}\text { lease agreement with } \\
\text { investment obligations } \\
\text { and other forms of }\end{array}$ & $4 / 3.5$ & - & $19 / 16.5$ \\
agreement & $30 / 26$ & $11 / 9.5$ & \\
\hline Total & & & \\
\hline
\end{tabular}

The dynamics of the spread of PPP/MPP and quasi-PPP forms by the periods of concluding real agreements is shown in Figure 1.

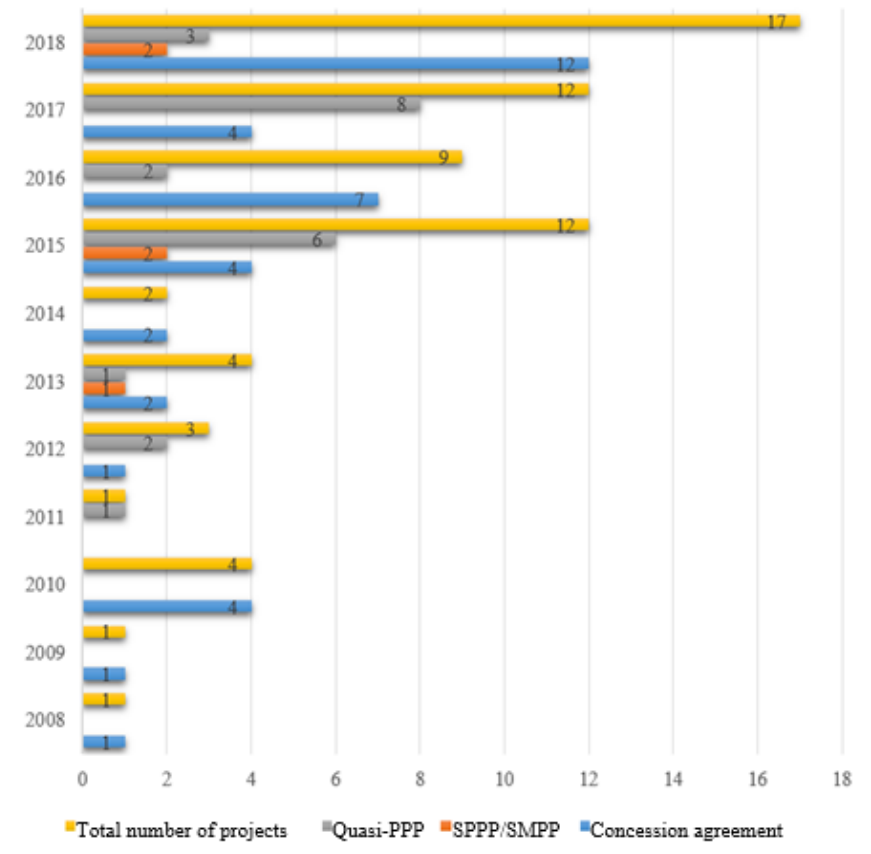

Fig. 1. Dynamics of concluding agreements as a part of a public-private partnership in the physical education and sports industry in Russia

Data on the status of the project are shown in Table 2. 
the first projects in the framework of public-private partnership in the field of physical education and sports were also implemented in the form of concession agreements. A feature of the development of the PPP sphere in Russia is the emergence of regional laws on PPPs before the federal law. The first PPP law appeared in St. Petersburg in 2006. By the beginning of the 2010s, similar laws existed in many regions. The first PPP agreements in the field of physical education and sports were based on regional legislation. The Federal Law on PPP was adopted in 2015. Since that time, the active use of the PPP/MPP agreement ha begun, but so far is more common in initiatives. In 2016, the Ministry of Economic Development of the Russian Federation prepared Recommendations for the Implementation of PPP projects. Best Practices, which describe in sufficient detail the mechanisms, tools, and principles for implementing PPP projects, including the specifics of the physical education and sports industry (using the case study). In 2017, Methodological Materials for the Authorities of the Constituent Entities of the Russian Federation on the Implementation of PPP-Based Projects for the Development of Sports Infrastructure, which discusses the prospects for the development of PPPs in the sports industry, an analysis of the forms of interaction between the authorities and business in the field of sports, as well as brief characteristics of standard projects for the reconstruction and construction of sports facilities have appeared.

\section{B. Features of the development of interaction between} business and the authorities in the field of sports in Russia

Most of the projects are implemented in the form of a concession agreement $(115-\mathrm{FZ})-55 \%$. The PPP/MPP Agreement (224-FZ) includes both the initiative of a public partner (classical competitive procedure) and a private initiative, usually implying either a simplified procedure for concluding an agreement or preferences for a private investor, which gives reason to argue that public-private partnership is currently the most common form of interaction between business and the authorities in the field of physical education and sports.

A feature of PPP in the field of physical education and sports is the absence of federal-level projects. Municipal projects predominate in terms of implementation - 66 $(57.4 \%)$, regional projects are less numerous, but regional projects are more significant in terms of investment. Data on the total investment required for the implementation of the project is presented for 98 of 115 projects and amounted to $198,262,252$ thousand rubles, of which 43 projects are regional, requiring 186,580,894 thousand total investments. Analysis of open sources of information and charters of projects allows us to judge that the public party, as a rule, is interested in implementing projects completely at the expense of a private investor, with rare exceptions.

An analysis of the functionality of the objects of PPP agreements in relation to sports has shown that multifunctional sports and recreation complexes, swimming pools, ice complexes, ice complexes, ski resorts, football complexes, stadiums, etc. are very popular. partnership in the field of sports are not accidental. First of all, they are tied to the development of the legislative and methodological framework. Thus, the law on concessions was adopted in Russia in 2005; therefore it is not surprising that 
So, in the megaproject of the 2012 London Olympics, the

Analysis of the state of the project by stages of implementation has shown that $18.3 \%$ of projects are at the investment stage, and $30 \%$ are at the operational stage, that is, less than half of the projects have received real investments. $42 \%$ of projects are in the process of initiation and structuring. As a rule, these are projects initiated by the public party and are in search of a private partner. In a number of cases, competitive procedures for these projects that did not lead to the conclusion of a contract were conducted. Moreover, such projects are listed in the database since 2013. An example is the project initiated in 2013 based on a concession agreement "Regional Swimming Center in Khabarovsk Krai" or in 2015, the "Creation and Operation of an Equestrian Sports Complex in Samara Region" project. Obviously, the public party did not find an investor ready to implement these projects.

Among the leading regions that successfully implement projects in the field of physical culture and sports with the involvement of a private partner, we can distinguish Lipetsk, Nizhny Novgorod, Novosibirsk, Rostov, Samara, Tyumen, Ulyanovsk Regions, the Republic of Udmurtia. These regions have experience in implementing more than one project under a concession, public-private partnership agreement, or a lease agreement with investment obligations. There are 30 regions that actually launched at least 1 similar project. In total, the activity of 43 constituent entities of the Russian Federation was recorded in the sphere of physical culture and sports. It should be noted that the activity of the regions in this area has a different quality. This is due to a number of circumstances, one of which is the emergence of obligations to create a register of PPP projects planned for implementation as a part of a regional development program. As mentioned earlier, today more than $40 \%$ of projects are at the initiation and structuring stage, which does not mean a real launch and implementation of the project. Moreover, the regions, in principle, have different levels of PPP development, which also affects the quality of the work of the authorities with a private investor. For example, when initiating PPP projects, the public party does not indicate the terms of the project, the form of cooperation, or the amount of investment in the Project Design Abstracts. Moreover, the public party often indicates that it is not ready to co-finance the project. All this allows us to assert that poor-quality project initiation will annually increase the share of projects that "did not find" an investor.

\section{The results of a study of large sports megaprojects in Russia}

The use of public-private partnership mechanisms in the implementation of international-level sporting events is not yet comprehensive. As a rule, this is not about a systematic approach with a thought-out mechanism of interaction within the framework of a megaproject, but about the implementation of individual projects for the construction and reconstruction of sports facilities.

The methodological basis for solving problems can be the use of framework standards for projection activities and past experience. Since the implementation of sports megaprojects is of a single nature, the importance of analogues is increasing.
UK PRINCE2 ${ }^{\circledR}$ (Projects IN Controlled Environments) national standard was used to organize managerial processes and procedures.

In Russia, the Sochi 2014 Olympics management team, having carefully studied the experience of other countries, partially used the best practices of the London Olympics. This led to the spread of the provisions of the PRINCE2 $\AA$ standard in the implementation of megasports such as the World Cup and Formula 1 and further influenced the organization of the management system in government bodies in the Russian Federation.

\section{Problems of interaction between the authorities and} business in the field of sports in Russia at the present stage

Researchers of the development of PPPs in the field of sports in Russia highlight such problems of interaction between the authorities and business as the lack of common standards in the construction of sports facilities, standard projects, developed measures of the State support, and low awareness of investors. Furthermore, the following problems were identified in the framework of this study:

- the high differentiation of the regions of the Russian Federation in terms of the level of implementation of PPP projects and project management as a whole prevents the replication of the experience of successful projects, the dissemination of best management practices;

- high turbulence of the external and internal environment, leads to the need to create a system mechanism for managing complex changes in projects, as well as preventive anti-crisis plans;

- low productivity and unsystematic work with stakeholders, which, in addition to interacting with public and private partners, includes the public and the population, which requires the creation of tools for the systematic work of communication and informing stakeholders;

- there is no single working database for all projects implemented within the framework of any form of interaction between the authorities and business, whether it is PPP, corporatization, tax incentives, etc.

\section{DISCUSSION OF THE RESULTS}

Thus, one of the most significant problems in the studied area is the lack of a unified working database for all projects implemented within the framework of any form of interaction between the authorities and business, the formation of which can make it possible to take into account the entire possible arsenal of tools of this partnership, especially to the regions that have no experience attracting private investors to the implementation of projects in the field of physical education and sports. A similar base will also be a center of knowledge on PPP projects, which will allow documenting the best practices and lessons learned and replicating the experience of the most mature regions. 


\section{References}

[1] T. E. Melnik. "Public-Private Partnership in the Field of Physical Culture and Sports,” Journal of Russian Law. vol. 12. Pp.133-141, 2016.

[2] Petrikova E.M., Slobodyanyuk N.V. "Financial Features of the PublicPrivate Partnership of the Sports Industry", Finance and Credit, 32 (560), 2013, pp.29-41

[3] A. D. Tsepeleva, "Public-Private Partnerships in the Sphere of Sports: foreign experience," Uchenye zapiski universiteta imeni P.F. Lesgafta. vol. 4(98), 2013, pp. 173-177

[4] A. D. Tsepeleva. Improving the Mechanism of Public-Private Partnership in the Field of Physical Education and Sports Services: Thesis for a Candicate Degree in Economics. SPb., 2015.

[5] A.V. Pochinkin, S.G. Seyranov. "Economics of Physical Culture and Sports": Monograph. M.: Soviet sport. 2011.

[6] I.N. Tkachenko, G.Yu. Pakhalchak, E.N. Starikov, et al. "A Study of Institutional Features the Formation and Development of the Mechanism of Public-Private Partnership (for example, the Industrial Complex of Sverdlovsk Region)": Monograph, Yekaterinburg: Ural State University of Economics Press, 2014.

[7] B.Flyvbjerg "What you should know about megaprojects and why: an overview" Project. Management Journal. vol.45 (2), 2014, pp. 6-19.

[8] Y. Li, Y. Lu, J.E. Taylor, Y. Han "Bibliographic and comparative analyses to explore emerging classic texts in megaproject management" International Journal of Project Management. 2018. vol.36 (2), pp.342361.

[9] A.K. Mazur, A. Pisarski, A. Chang, N. Ashkanasy "Rating defence major project success: the role of personal attributes and stakeholders relationships" International Journal of Project Management, vol.32 (6), 2014. pp. 944-957.

[10] J.G. Geraldi, L. Lee-Kelley, E. Kutsch "The titanic sunk, so what? Project manager response to unexpected events" International Journal of Project Management. vol. 28 (6). 2010. pp. 547-558.

[11] S.X. Zeng, H.Y. Ma, H. Lin, R.C. Zeng, V.W.Y. Tam "Social responsibility of major infrastructure projects in China" International Journal of Project Management. vol. 33 (3). 2015. pp. 537-548.

[12] T. Enright "The great wager: crisis and mega-project reform in $21^{\text {st }}$ century Paris" Camb. J. Reg. Econ. Soc. 2014. vol. 7 (1), pp.155-170.

[13] N.D. Long, S. Ogunlana, T. Quang, K.C. Lam "Large construction projects in developing countries: a case study from Vietnam" International Journal of Project Management. 2004. vol. 11 (6), pp. 404413.

[14] J.K. Pinto "Project management, governance, and the normalization of deviance" International Journal of Project Management. vol. 32 (3). 2014. pp. 376-387.

[15] J. Eweje, R. Turner, R. Müller "Maximizing strategic value from megaprojects: the influence of information-feed on decision-making by the project manager". International Journal of Project Management 2012. vol.30 (6). pp. 639-651.

[16] H.Thamhain "Managing risks in complex projects" Project. Management Journal. vol.44 (2). 2013. pp. 20-35.

[17] A. Davies, I. Mackenzie "Project complexity and systems integration: Constructing the London 2012 Olympics and Paralympics Games". International Journal of Project Management. vol. 35 (5). 2014. 773-790.

[18] C.P. Barros, M. Ibrahimo, S. Szymansky "Transatlantic sport: the comparative economics of North American and European sports" Edward Elgar pub. 2003. 170 p.

[19] E. Barget, J.-J. Gouguet. "The Total Economic Value of Sporting Events Theory and Practice" Journal of Sports Economics. vol.8(2). 2009. pp. 165-182.

[20] R. Osei-Kyei, A.P.C. Chan "Review of studies on the Critical Success Factors for Public-Private Partnership (PPP) projects from 1990 to 2013" International Journal of Project Management. vol. 33, 2015. pp. 1335-1346.

[21] C. Cui, Y. Liu, A. Hope, J.Wang "Review of studies on the publicprivate partnerships (PPP) for infrastructure projects" International Journal of Project Management. vol. 36, 2018, pp. 773-794. 